\title{
A methodology for facing the accessibility of monuments developed and realised in Thessaloniki, Greece
}

\author{
Aristotelis Naniopoulos and Panagiotis Tsalis
}

\author{
Aristotelis Naniopoulos is \\ Professor of Transport \\ Systems and Panagiotis Tsalis \\ is Doctor and Civil and \\ Transportation Engineer, both \\ at Transport Systems Research \\ Group, Faculty of Engineering, \\ Aristotle University of \\ Thessaloniki, Thessaloniki, \\ Greece.
}

\begin{abstract}
Purpose - Archaeological sites and monuments, by their nature, do not allow major interventions to their structure, in order to abolish the obstacles that make them inaccessible. Any interventions should be made sensitively and carefully, so as not to alter the monument's character or damage it, either visually or structurally. The project "PROSPELASIS" focused on creating a methodology for facing monuments' accessibility and perceptibility problems for people with disabilities and testing its application at Byzantine monuments of Thessaloniki. The paper aims to discuss these issues.

Design/methodology/approach - The creation of the proposed methodology was based on both research in relevant bibliography and the application of a form of "Delphi method" among involved actors. In this process persons specialized in accessibility and disability issues, persons with disability themselves, as well as employees of the 9th Ephorate of Byzantine Antiquities, archaeologists and experts in monuments' restoration, participated.

Findings - The possible sites of interest for visitors with disabilities examined amount to 20 monuments which document the evolution of Byzantine architecture and are included in UNESCO's World Heritage List. In six major monuments (Acheiropoietos, Saint Demetrios, Saint Nicholaos Orphanos, Hagia Sofia, Rotunda, Heptapyrgion Fortress) significant accessibility improvements were realized in order to verify the methodology proposed.

Practical implications - A practical tool for improving monuments' accessibility has been developed, open for use by any interested body.

Social implications - The application of the methodology developed is beneficial for the promotion of the equality and non-discrimination principles.

Originality/value - The successful implementation of the proposed methodology and the importance that accessibility improvement of monumental sites has in the attraction of visitors with restricted mobility and perceptibility and the development of accessible tourism, constitute the results of this project not only pertinent to Thessaloniki or Greece, but worthy of a wider application.
\end{abstract}

Keywords Methodology, Cultural tourism, Tourism industry, Accessibility of monuments, Future tools and methods, PROSPELASIS

Paper type Research paper

(c) Aristotelis Naniopoulos and Panagiotis Tsalis. Published in the Journal of Tourism Futures.

This article is published under the Creative Commons Attribution (CC BY 4.0) licence. Anyone may reproduce, distribute, translate and create derivative works of this article (for both commercial and non-commercial purposes), subject to full attribution to the original publication and authors. The full terms of this licence may be seen at: http://

creativecommons.org/licences/by/ 4.0/legalcode

\section{Introduction}

A need to modernize the European tourism policy and offer has been identified in order to maintain Europe's tourism leadership. Diversifying tourism products and capitalizing on rich heritage (natural, cultural, historical, industrial, etc.) is the first priority listed in the European Commission's Action Plan for tourism issued in 2010 (European Commission (EC), 2010).

The European Union (EU) aims at the promotion of tourism products which reflect its heritage and make Europe a unique tourism destination. This has led to EU initiatives such as the Capitals 
of Culture, the European Heritage Days and the European Heritage Label. At the same time, the European Commission aims to look for synergies with similar initiatives of other international and European organizations, such as the "Cultural Routes" programme of the Council of Europe (CoE), the UNESCO world heritage sites or the "Silk Road" project of the UNWTO (EC, 2014).

A "tourism product" represents a combination of different aspects (characteristics of the places visited, modes of transport, types of accommodation, specific activities at destination, etc.) around a specific centre of interest, such as visits to historical and cultural sites, visits to a particular city, etc. This notion of "tourism product" is used by professionals in the tourism business to market-specific packages or destinations. It is then possible to speak of specific types of "tourism products", such as culinary tourism, ecotourism, health tourism, winter tourism, cultural tourism, etc. (United Nations (UN), 2008).

Thus, tourism is directly related to cultural and natural heritage as well to traditions and contemporary cultures of the EU. Cultural heritage, natural resources and the climate have been identified as significant factors contributing to the attractiveness and competitiveness of a country as a tourist destination and cultural and natural heritage have gained an increasing significance at different levels of the economy (Van der Auwera and Schramme, 2014). Thus, in recent years there is an increasing effort aiming at ensuring that heritage spaces, including monuments and archaeological sites, can be used by modern society as social asset, retaining at the same time their connection with the social, economic, political, religious and cultural context of the place and time of their creation.

Diversifying European tourism products is only one aspect of what Europe should do to remain competitive. The Action Plan for tourism issued in 2010 underlies the need to guarantee optimum conditions for services and safety, particularly when catering for elderly people or those with reduced mobility. The UN Convention on the Rights of People with Disabilities has been concluded by the EU and ratified by 22 member states, while the rest are in process of doing so. State Parties to the Convention must ensure access for persons with disabilities to tourism venues according to Article 30. Furthermore the Convention under Article 9, request State Parties to ensure to person with disabilities access on equal basis with others, access to the physical environment, transportation, information and communications and to other facilities and services open or provided to the public (UN, 2006). Thus, in order for monuments to become a social asset, physical access to them for all social groups, including the elderly and persons with restricted mobility, as well as the understanding of their historic and artistic character play an important role.

\section{Aim of the study}

A visit to an archaeological site or monument is an original, unique experience that constitutes the main attraction in Greece for tourists. Although there are movable findings from all historical periods of Greece in museums around the world, the archaeological sites and monuments can be found only within the initial geographical boundaries. A visit to a monument allows the composition of all stimuli into a unique experience, consisting of the following:

- visual stimuli: shapes, colours, textures, images, sense of the real scale of the site;

- tactile stimuli: the floor's texture and the way in which it is perceived (e.g. gravel or stone) or the texture of the seats (e.g. wood, marble, metal);

- auditory stimuli: the soundscape of the surrounding area, either natural or artificial, the sound of interaction between man and the environment, walking, the swish of plants when walking through them;

- olfactory stimuli: natural scents (depending on the season, time, weather) and artificial scents (e.g. scents of diverse materials or deliberately diffused scents and incenses); and

- gustatory stimuli: tastes referring to the site and underlining its uniqueness, such as fruits from the trees of a garden, the water of a fountain, the treat in a monastery.

In Thessaloniki, a city with rich heritage which has lost its historic character to a great extent, monuments constitute isolated "islets", without any visual connection between them, making 
their identification, their understanding and physical access to them difficult for visitors in general and persons with restricted mobility in particular. This problem is exacerbated by the fact that the current city's ground level is often four to five metres above the level where the entrance to the city's monuments is. Thus, it became obvious that any attempt to "socialize" the cultural heritage of the city should pursue the following two objectives: to provide easy access to monuments for all visitors, including persons with disability and restricted mobility; and to help visitors through the provision of adequate information and the indication of ways of moving from one monument to another, connecting the "pieces of the puzzle" and composing an integrated picture of the city in different historical phases (Naniopoulos et al., 2011b).

It should also be noted that archaeological sites and monuments, by their nature, do not allow major interventions to their structure in order to remove obstacles that make them inaccessible. We all wish that all areas in a monument could become accessible. However, if that is not possible this should be determined in advance. Thus, a methodology which would identify potential problems with a monument's accessibility, help determine the areas that can become accessible and pinpoint the necessary actions, is deemed necessary.

In the present paper, a methodology for the improvement of the accessibility of archaeological sites and monuments for visitors with restricted mobility which was realized in the frame of the PROSPELASIS project is presented. The project was financed by a grant from Iceland, Liechtenstein and Norway through the EEA Financial Mechanism 2004-2009 (50 per cent) and from the public investments programme of the Hellenic Republic (50 per cent). It was realized through a cooperation of the Aristotle University of Thessaloniki (AUTh: project promoter) and the 9th Ephorate of Byzantine Antiquities and focused on the improvement of the accessibility of Thessaloniki's Byzantine monuments, most of which are included in UNESCO's World Heritage List.

It should be noted that UNESCO is focusing in particular on the connection between cultural heritage and development through the Mexico City Declaration on Cultural Policies (UNESCO, 1982) and the Report of the World Commission on Culture and Development "Our Creative Diversity" (UNESCO, 1996). Today, cultural heritage, in particular, is perceived as an important vehicle for development since "cultural tourism contributes to economic development" and "cultural heritage builds social cohesion" (UNESCO, 2010; Van der Auwera and Schramme, 2014).

\section{Methodology}

The concept of accessibility, as used here, includes two different concepts:

1. accessibility of an area, which means the usability and possibility of independent physical access and movement around the monuments; and

2. perceptibility, referring to the way one perceives, understands the environment and learns from it (Naniopoulos and Marki, 2003; Fertier, 2003).

The creation of a methodology for the improvement of monuments' accessibility was based on both research in relevant bibliography and the application of a version of "Delphi method" among involved actors, in order to identify the obstacles that citizens with disabilities face in accessing and perceiving monuments as well as the obstacles and challenges concerning the process of making monuments accessible. In this process, persons specialized in accessibility issues, persons specialized in disability issues, persons with disability themselves as well as employees of the 9th Ephorate of Byzantine Antiquities, archaeologists and experts in monuments' restoration participated.

More specifically, the process involved:

- Research of existing practices concerning accessibility improvement procedures in monuments and archaeological sites, such as the guidelines published by English heritage (English Heritage, 2004, 2005).

- Focus on accessibility policies employed by monuments' managerial authorities, mostly based on National Disability Authority of Ireland (NDA) (2011) "Code of practice on accessible heritage sites". 
- Creation of the basic structure of the methodology, based on the methodology proposed during the research project "Archaeology for all" which was realized in 2003 through a cooperation of the AUTh and the 9th Ephorate of Byzantine Antiquities (Naniopoulos and Marki, 2003).

- Development of a task model for users of the basic groups of people with restricted mobility and perceptibility, according to the standards set by the European projects TELSCAN and TELAID. In this, measurable and observable tasks, that are critical to the performance of a larger specific activity by visitors to the monuments with restricted mobility as well as accessibility problems, are identified (Tsalis and Naniopoulos, 2008; Naniopoulos, 2001). The task model was finalized with the cooperation of local associations of persons with restricted mobility, mostly the Panhellenic Association of Paraplegics, the Panhellenic Association of the Blind and the Union of Deaf Persons of Northern Greece.

- Examination of existing accessibility evaluation methodologies. These included methodologies and guidelines developed by the Department of Transport and the Royal National Institute for the Blind in the UK, the ADA standards in the USA, as well as Greek guidelines (Department for Transport (DfT), 2002, 2007; Royal National Institute for the Blind (RNIB), 1995; Transport Systems Research Group of AUTh (TSRG), 2005; Greek Ministry of Environment, Land Planning and Public Works (GMEPW), 2003; Americans with Disabilities Act Accessibility Guidelines (ADAAG), 1992).

- Development of a methodology for the examination of infrastructure's accessibility. Since the previously mentioned methods and guidelines referred to accessibility of infrastructure in general and not to monuments in particular, they were further enhanced according to the data of the developed task model level and verified with the participation of users and persons specialized in accessibility and disability, including architects specialized on accessibility, sign language interpreters, mobility trainers for blind people as well as persons with disability.

- Pilot implementation of the developed methodology and restructuring according to the results of the in situ application.

- Finalization of the proposed methodology and implementation in six Byzantine monuments of Thessaloniki.

\section{Results}

The methodology developed, which can be applied to deal with the problem of accessibility and perceptibility of monuments and archaeological sites, is presented in Figure 1 of the next page. As has already been mentioned, in many cases not all parts of a monument can become accessible. Thus, from the first stages of a study, one should determine the parts of a monument that can be made accessible, as well as those that do not provide this possibility, through sufficient vindication and documentation (Naniopoulos et al., 2009a, b).

The different components of this methodology are presented as follows.

\subsection{Evaluation of existing accessibility}

4.1.1 Definition of the population groups for whom accessibility and perception must be ensured. Ideally, all potential visitors should have the possibility to access all areas of a monument. If this is not feasible, the next goal should be to ensure accessibility and perceptibility for as many visitors as possible.

Each of the main groups of people with restricted mobility can be divided in subcategories. There are also people with multiple disabilities. In specific cases and according to the objectives of a study, a certain categorization can be adopted. Accessibility and perceptibility requirements of an area in relation to different groups of people with disabilities can be systematically examined by using the concise "task model" developed, that is by using the recording the sequence of actions-needs of a monument's visitor. Problems and respective possible solutions can be formulated using this "task model" for each main group of people with disabilities utilizing the principles of Inclusive Design (Naniopoulos and Marki, 2003; Naniopoulos et al., 2011a) (Figure 2). 


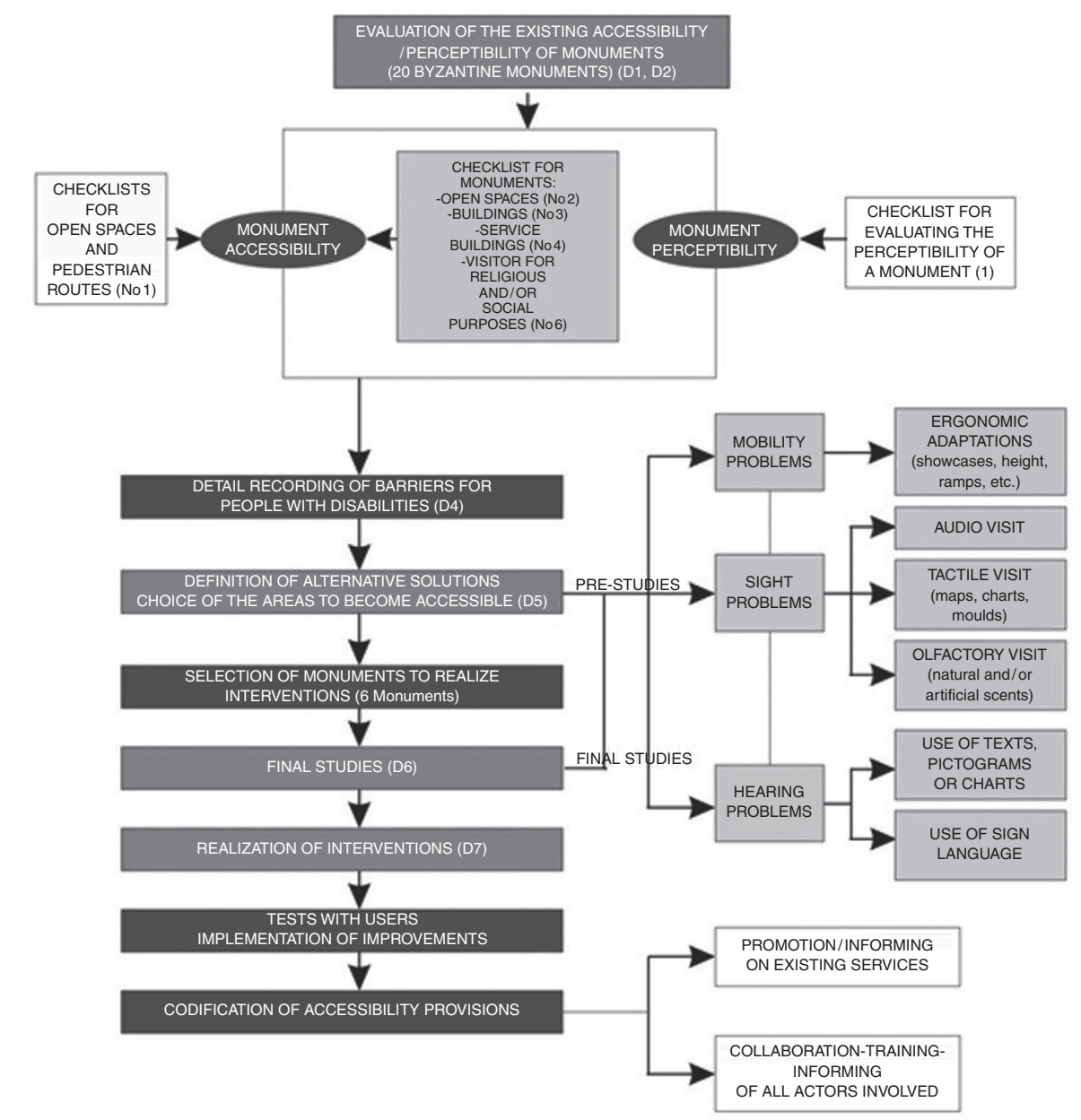

4.1.2 The methodology for examining the existing situation. Figure 1 explains the approach followed for examining the existing situation.

The first stream of actions concerns the development, verification and application of checklists. Six types of checklists have been developed:

1. checklist for open spaces, pedestrian routes (access to the monument) and methodology for its application;

2. checklist for evaluating the accessibility of monument's open spaces;

3. checklist for evaluating the accessibility of monument's buildings;

4. checklist for evaluating the accessibility of monument's service buildings;

5. checklist for evaluating the perceptibility of the monument and its open space; and

6. checklist for evaluating the possibility of a person with disability to participate in religious ceremonies (of the Greek Orthodox Church) or in related social activities:

- The first checklist concerns the evaluation of the approach route to the monument. It is a detailed checklist which includes the evaluation of elements such as: bridging levels, sidewalks, lighting, street furniture, road crossings, bus stops, stairs, parking spaces, public lavatories, perceptual organization of the environment. 
Figure 2 Task model of monuments' visitors

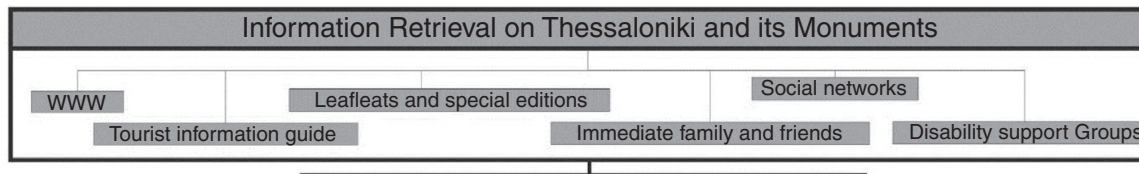

Deciding to Visit Thessaloniki


\begin{tabular}{|c|}
\hline Exiting the Monument \\
\hline Departing from the Monument \\
\hline
\end{tabular}

- The second checklist concerns the evaluation of monument's open spaces as well as open space monuments including elements such as: bridging levels, open space furniture, stairs, public lavatories, perceptual organization of the environment.

- The third checklist concerns the evaluation of the monument's building itself, including elements such as: general information, entrance, circulation, horizontal and vertical movement, services, emergency evacuation, signing, acoustics and lighting.

- The fourth checklist concerns the evaluation of the monument's service buildings including elements such as: general information, entrance, circulation, horizontal and 
vertical movement, services, emergency evacuation, signing, acoustics, lighting, closed spaces/educational/activities rooms, closed spaces-offices, closed places gastronomic halls, closed spaces-transaction shops, reception desks.

- The fifth checklist concerns the evaluation of the monument's perceptibility including elements such as: general services provided, perceiving the monument and relevant information.

- The sixth checklist is a supplement to the previous ones and is used in case that a monument is used for religious and related social purposes. All the monuments examined in the project are also used also for religious and related social purposes. Therefore the list takes into consideration the processes, activities and ethics followed in the Greek Orthodox Church (Naniopoulos et al., 2009b).

Figure 3 provides a brief picture of the checklists and their content. Not all the checklists or all their elements are applicable for every monument. Attention has been paid to create exhaustive checklists that cover as many issues as possible, and also to guide the researcher not to forget important elements, such as colour contrast, tension of door openings and way finding, etc.

The development of the checklists is based on the results of the PROSPELASIS Deliverable D1: "Determination of population groups and description of a task model". These were used for examining the existing situation concerning accessibility, usability and perceptibility of monuments approach routes, monuments' open spaces, monuments' buildings as well as monuments' service buildings. The application of checklists was realised by appropriately trained personnel of the Transport Systems Research Group of AUTh.

For recording the findings, relevant maps and layouts provided by the 9th Ephorate and relevant laboratories of AUTh were used. Documentation of observations was supported by photographs and measurements, where necessary.

\section{Figure 3 The checklists developed}

1. Physical access to the monument and relevant checklists

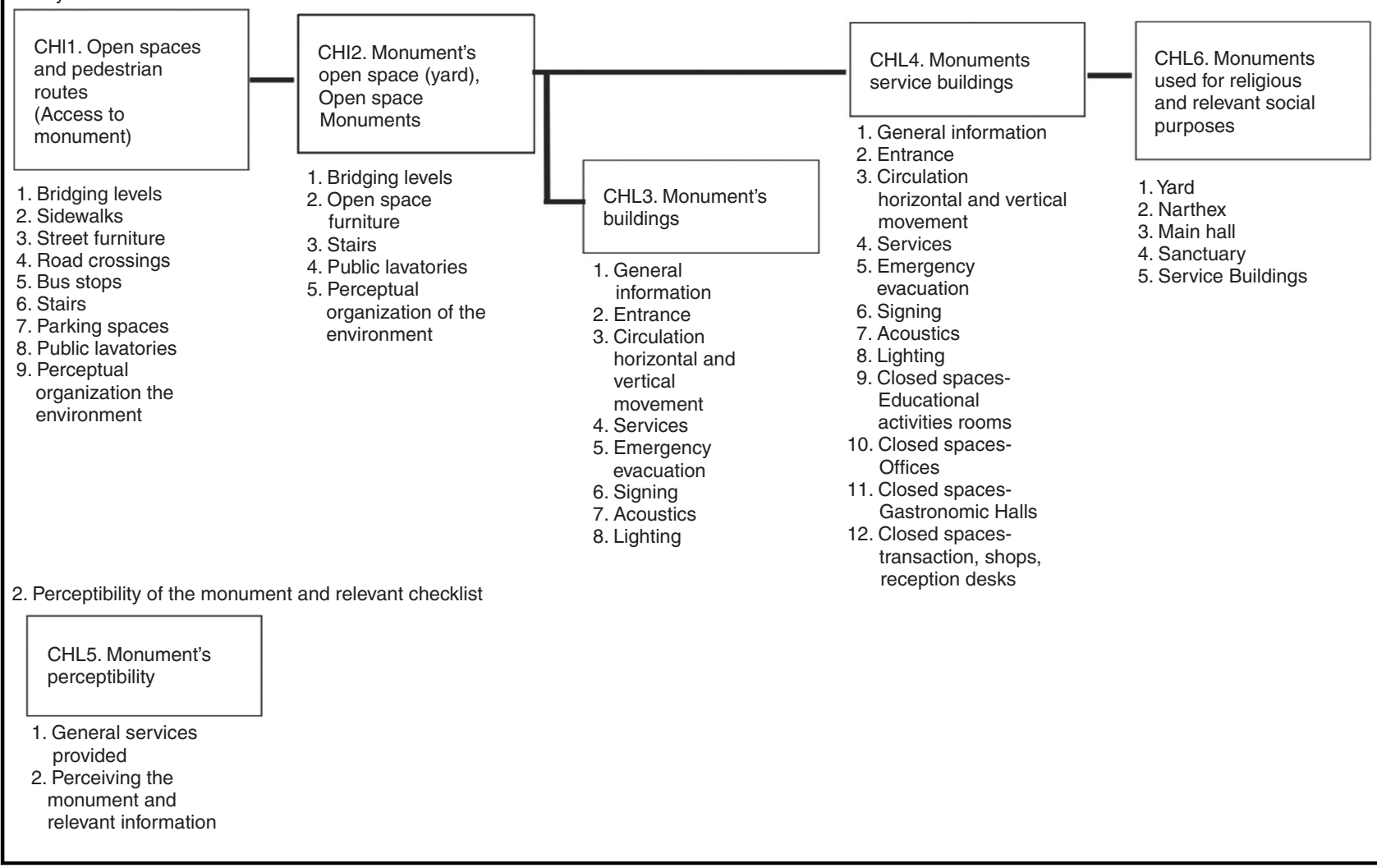


4.1.2.1 Application of the methodology for examining the existing situation in Thessaloniki's Byzantine monuments. A team, consisting of architects and civil engineers, was formed and trained appropriately concerning the application of the checklists. The same people participated in all the evaluations in order to have a more complete view of the problems encountered and, thus, guide the design team towards the appropriate solutions. The data collected were used to prepare a relevant report for each monument examined. In total 18 reports were prepared for the UNESCO-protected Byzantine monuments:

- Churches of Acheiropoietos, Saint Catherine (Hagia Ekaterini), Holy Apostles (Hagioi Apostoloi), Saint Demetrios (Hagios Dimitrios), Christ Saviour, Nicholas Orphanos, Panagia Chalkeon, Saint Panteleimon (Hagios Panteleimon), Prophet Elias, Hagia Sofia, Timios Prodromos;

- Rotunda;

- Latomou and Blatades Monasteries;

- City Walls;

- Heptapyrgion Fortress;

- Trigonion Tower; and

- Byzantine Bath.

In addition, two reports were prepared for Byzantine monuments of the city which are not included in the UNESCO list, the Taxiarchon Church and the Basilica \& Martyrium of 3rd September str.

An evaluation report was prepared for each monument. Approach routes and obstacles are noted for all 20 monuments on their layouts, while relevant text and photos show the obstacles identified (Naniopoulos et al., 2010a) (Figure 4).

Some of the major obstacles identified included:

- significant height difference between the monuments' yard and the adjacent pavement (the yard being at a lower level than the pavement surrounding it), bridged only with staircases, making access for wheelchair users impossible;

- height differences in the monuments' interiors making horizontal circulation difficult for visitors with restricted mobility;

- lack of information about the monuments; and

- lack of provisions for visitors with sensory impairments.

\subsection{Definition of alternative solutions and implementation of accessibility improvements}

The evaluation of the monuments' existing accessibility level is essential for the definition of alternative solutions for accessibility improvements. In the PROSPELASIS project intervention proposals were completed in pre-study level for all of the examined monuments (Naniopoulos et al., 2010b).

The amount of budget and time allocated to monuments' interventions during the PROSPELASIS project did not allow for implementation of accessibility improvements at all of the examined monuments. Thus, a multi-criteria analysis was applied in order to select in total six major monuments (Acheiropoietos, Saint Demetrios, Saint Nicholas Orphanos, Hagia Sofia, Rotunda, Heptapyrgion Fortress) where the design team proceeded with final studies and where significant improvements in their accessibility were realized (Naniopoulos et al., 2011a).

The criteria for selecting the monuments were the following:

- $\mathrm{C}_{1}$ : cultural-historical significance of the monument. How important is the monument for world heritage? Is it well known, what particular elements are important form cultural and historical point of view? (range 1-10). 





- $\mathrm{C}_{2}$ : religious significance. Is the monument significant from a religious point of view? (range 1-10).

- $\mathrm{C}_{3}$ : number of visitors the monument attracts (range 1-10).

- $\mathrm{C}_{4}$ : feasibility and cost of proposed interventions (range 1-10).

Members of the 9th Ephorate of Byzantine Antiquities as well as members of the PROSPELASIS design team were asked to consider the above mentioned characteristics of monuments and provide marks. The marks given by the Ephorate were multiplied by 2, while the design team's by 1 . These were added and the sum was divided by $3 \times 20$ giving an average weight for each criterion (where the Ephorate's opinion weighs double that the designer team's).

The above-mentioned process led to the implementation of the following interventions:

- Installation of two lifts and creation of a new staircase at Acheiropoietos bridging the height difference between the monument's yard and the adjacent pavement.

- Creation of a metal bridge and a new staircase and installation of a lift at Rotunda, giving direct access to the monument's interior. This was achieved through the use of the "Imperial Gate" of the monument, recreating the so called "Royal route".

- Opening of the secondary gate and creation of a heavy duty ramp at the Heptapyrgion fortress.

- Creation of an accessible toilet at the Saint Demetrios church.

- Installation in the six monuments of a WiFi system providing text and audible information in Greek, English and Russian as well as information in Greek and International Sign Language.

- Creation of two tactile models for visitors with restricted vision in Rotunda and Heptapyrgion.

- Creation of a "cultural route" connecting three major Byzantine monuments (Acheiropoietos, Rotunda and Hagia Sofia) (PROSPELASIS team, 2012).

The aesthetic value of the realized interventions was ensured through the participation in the design process of two famous Greek artists, Cris Giannakos (whose work revolves around ramp design) and Constantin Xenakis (whose work focuses on a poetic implementation of signage).

It should be noted that, in order for the PROSPELASIS team to proceed with their implementation, the above mentioned interventions had to be approved by the Greek Central Archaeological Council (CAC). The CAC is the highest advisory body on all matters pertaining to the protection of ancient monuments, archaeological sites and sites of exceptional historical or legendary importance up to 1830. Rapporteurs to the CAC are the respective heads of Directorates of the Ministry's Central Services depending on the issue to be discussed. In the PROSPELASIS case, the head of the Directorate of Restoration Works presented the PROSPELASIS team proposed interventions, together with the opinion and recommendation of the MCT Directorates' opinion. The PROSPELASIS team, which consisted of AUTh researchers and the Ephorate's archaeologist were invited to answer certain questions and present different alternatives with the approved ones implemented in the selected monuments.

\subsection{Promotion-information on accessibility and perceptibility of archaeological sites and monuments of an area}

People with disabilities tend to plan their route carefully and make sure in advance that they have reliable information on the accessibility of their destination. They should be given the appropriate information on existing conditions and the means that are available, in order to make their transport to and from the monument easier, and to help them get as much information as possible (Weisen, 2003; RNIB, 2003). Through the internet, users can access a great quantity of data, depending on their needs, such as ergonomic information, photos, etc. At the same time, there can be printed guide-books with selected information for those who are not familiar with the internet. 
In the PROSPELASIS project provision of info is achieved through the creation of the aforementioned WiFi system, the installation of information columns depicting the available provisions outside of the monuments that form the "cultural route", the project's web site and dissemination activities.

\subsection{Collaboration of all sides involved}

In order for an accessible transport chain to function, for a monument to be accessible and for its perceptibility to be improved, all sides involved must collaborate and each one's role must be promoted. The sides involved include:

- local authorities;

- associations of people with disabilities;

- monument staff;

- the authorities managing a monument; and

- people working in tourism industry.

4.4.1 Training and informing of people involved. All the people involved in the function of an archaeological site or monument - guards, guides, tourist agents, scientific personnel of the institution - must be informed and receive quality disability equality awareness training. In particular:

- accessibility policy responsibilities should be allocated based on the degree of competence, experience and training of the participants;

- training courses and promotional events for staff on a regular basis to enable all users of the monument/open space, service provision or facilities to be aware, and follow the requirements of, the policy.

In the PROSPELASIS project there was a continuous cooperation with all involved actors including staff of the Ephorate of Byzantine Antiquities and of Ministry of Culture, staff of various disciplines of the Aristotle University, associations of persons with disabilities, people working in the tourist industry. As far as training actions are concerned, five training seminars were carried out in order to familiarize involved actors with several aspects of disability and accessibility, such as the following:

- needs of visitors with disability at monuments and archaeological sites;

- behaviour of monuments' employees toward visitors with disability;

- development of accessible tourism;

- maintenance and management of accessibility improvement interventions; and

- continuing the monument's accessibility task after PROSPELASIS.

\section{Future applications}

Making tourism facilities more accessible to people with disabilities, is considered a "golden opportunity" for businesses. In Europe it is estimated that at least 80 million people have a declared disability, a number due to increase because of demographic ageing and the correlation between disability and old age. Yet, this market appears not to be served properly $(E C, 2014)$.

Despite the existence of different legal provisions in the EU dealing with equal opportunities, there appears to be a general "inertia" among providers of tourism services in engaging in accessible tourism. It has been observed that the lack of awareness of accessibility and the lack of a convincing business case for accessibility training are amongst the key barriers hampering tourism enterprises from fully mainstreaming accessibility in their strategies and investments (EC, 2014).

As long as accessible tourism remains a poorly understood market, prospective tourism entrepreneurs have little incentives to engage in accessibility - let alone to engage in tourism accessibility training for themselves or foresee such training for their staff. 
At the same time, Europe is a key cultural tourism destination, with a large number of major cultural sites and a strong flow of culturally motivated visitors. It is estimated that cultural tourism accounts for around 40 per cent of all European tourism. The great variety of European cultural heritage - both material and immaterial - represents an important competitive advantage. Moreover, investing in cultural tourism is a way to ensure that benefits go to all citizens, a wide range of SMEs, generating new tourism flows, new jobs, new cultural and creative industries and opportunities for regional growth. Cultural heritage is indeed not concentrated in European capitals and cities, but is spread all over European territories (EC, 2014).

The methodology developed in the "PROSPELASIS" project caters for both of these tourist fields, developing a synergy between cultural heritage tourism and accessible tourism and combining two continuously developing tourism sectors of particular interest to European countries in general and Greece in particular.

Furthermore, it should be noted that the methodology developed does not rely on a particular country's local legislation, characteristics and authorities' structure. Thus, the PROSPELASIS methodology can be applied for implementing accessibility improvement interventions in monuments and archaeological sites at European or international level, with proper adjustments depending on each particular case.

As has already been mentioned, lack of right attitudes either discourage the potential traveller from setting on a journey or can turn a travel experience into an adventure to forget.

In order to surpass this obstacle, all the stakeholders involved in the everyday activities taking place at an archaeological site or monument - guards, guides, tourist agents, scientific personnel - must receive quality disability awareness training. This was achieved in the PROSPELASIS project with the five training seminars that were carried out in order to familiarize involved actors with several aspects of disability and accessibility and which created both a "critical mass" of stakeholders who have received disability equality training and useful material which could be utilized in future training activities.

Moreover, the cooperation between involved stakeholders, established through the PROSPELASIS project, has started bearing fruits. Common actions concerning access to Thessaloniki's cultural heritage have already been initiated, with the Museum of Byzantine Culture of Thessaloniki, in cooperation with the local Association of the Blind, creating a tactile tour for blind visitors of particular artefacts exhibited at the Museum, based on the methods followed in PROSPELASIS for the description of monuments' tactile models (Museum of Byzantine Culture (MBC), 2014).

Finally, it should be noted that the utility of the methodology created has already been recognized:

- by the UIA (Union Internationale des Architectes) awarding members of the PROSPELASIS team an "honorary award" for the interventions realized in Rotunda; and

- by the local scientific community, with the authors presenting it as part of a "lifelong learning" programme focusing on culture and special education which was organized by the University of Athens, the University of Thessaly and the University of Macedonia.

\section{Conclusions}

Addressing, at international level, the problems of protection, conservation, restoration and management of historical centres, archaeological sites, architectural aggregations, monuments and works of art, gradually led to the formation of a particular scientific field with a very wide subject area and interdisciplinary interfaces, which is not covered, as before, by the content of the History of Architecture and Art. Today, we are not only interested in the monuments' past; we are also interested in their present and future. We are interested in the monuments' preservation, restoration and emergence in direct relation to their present and future environment, their integration into modern life and their connection with economic, educational, tourist and social aspects in particular. Therefore, the practice applied up to date where the difficult task of protection, preservation, restoration and management of monuments, was assigned only to archaeologists, art historians and, at best, non-specialized architects would no longer have the desirable results. 
All actions concerning the accessibility, usability and perceptibility of a city's monuments and archaeological sites cannot be fragmentary. On the contrary, they must comply with a "systems approach", according to which all necessary measures and actions are considered in a way that promotes the principles of Inclusive Design, accessibility and perceptibility throughout the entire "chain" related to a person's transport and reception in a site of interest.

Promotion of accessibility, usability and perceptibility of archaeological sites and monuments for people with disabilities is desirable for social, financial and political reasons.

Improving accessibility of cultural spaces provides people with disabilities with the opportunity to live the unique experience of visiting a monument or an archaeological site.

The fact that a large number of archaeological sites and monuments exist in Greece is particularly important, since they are a unique feature and a powerful attraction for tourists. In Thessaloniki in particular, there are numerous monuments that could become friendlier to all visitors and not just to people with disabilities, if their accessibility and perceptibility were improved with the necessary interventions.

The methodology devised in the PROSPELASIS project creates a structured process assisting those responsible in improving monuments' and archaeological spaces' accessibility level and provides a "step by step" guide for the successful implementation of accessibility improvement interventions in monuments and archaeological sites. The analytical nature of the methodology for the examination of the existing situation ensures easy application, while its implementation in Byzantine monuments of Thessaloniki has verified its applicability and usefulness. The tools required for applying the methodology developed (e.g. checklists) are available at the public documents of the PROSPELASIS project's web site (http://prospelasis.com/).

\section{References}

Americans with Disabilities Act Accessibility Guidelines (ADAAG) (1992), "Checklist for buildings and facilities", available at: www.access-board.gov/adaag/checklist/a16.html (accessed 20 October 2008).

Department for Transport (DfT) (2002), Inclusive Mobility, DfT, London.

Department for Transport (DfT) (2007), Manual for Streets, DfT, London.

English Heritage (2004), Easy Access to Historic Buildings, EH, Swindon.

English Heritage (2005), Easy Access to Historic Landscapes, EH, Swindon.

European Commission (EC) (2010), Europe, the World's No. 1 Tourist Destination - A New Political Framework for Tourism in Europe, EC, Brussels.

European Commission (EC) (2014), Transnational Cultural Tourism Products and Tourism and Accessibility for All - Call for Proposals, EC, Brussels.

Fertier, A. (2003), "EUCREA International: policy, objectives and programme of action", Access to Culture and Sports for People with Disabilities Conference Proceedings, Hellenic Ministry of Culture, Thessaloniki, 30 October-1 November.

Greek Ministry of Environment, Land Planning and Public Works (GMEPW) (2003), Designing for All, MELPPW, Athens.

Museum of Byzantine Culture (MBC) (2014), "Touch and discover Byzantium - an audio - tactile tour for blind and visually impaired visitors”, available at: http://mbp.gr/images/Ekdoseis/pdf_entypa_MBP/Tyfloi\% 2016selido\%2021×29cm\%20 EN_VIEW.pdf (accessed 18 May 2015).

Naniopoulos, A. (2001), "Accessible and usable for all transport telematic systems", 9th International Conference on Mobility and Transport for Elderly and Disabled People, TRANSED, Warsaw, 2-5 July.

Naniopoulos, A. and Marki, E. (2003), "Accessibility and comprehensibility of monuments and archaeological sites for people with restricted mobility. A preliminary-investigation for the application of a methodology on sites of the 9th Ephorate of Byzantine Antiquities", Access to Culture and Sports for People with Disabilities, Conference Proceedings, Hellenic Ministry of Culture, Thessaloniki, 30 October-1 November.

Naniopoulos, A., Tsalis, P., Gerasimidis, S. and Kyriakopoulos, N. (2009b), D2: Methodology for the Examination of the Existing Situation, PROSPELASIS project Deliverable, AUTh, Thessaloniki.

Naniopoulos, A., Tsalis, P., Lazaridou, P., Kyriakopoulos, N. and Sakantamis, K. (2009a), Determination of Population Groups and Description of a Task Model, PROSPELASIS project Deliverable, AUTh, Thessaloniki. 
Naniopoulos, A., Giannakos, C., Xenakis, C., Papanikolaou, E., Kalliagra, S., Kourbeti, C., Tselegidis, I. and Digbasbani, A. (2010b), Proposal of Functional Alternative Solutions in Pre-study Level for Selected Monuments/Spaces, PROSPELASIS project Deliverable, AUTh, Thessaloniki.

Naniopoulos, A., Papanikolaou, E., Kalliagra, S., Tsalis, P., Palantzas, G., Nalmpantis, D., Genitsaris, E., Kyriakopoulos, N. and Tokmakidis, P. (2010a), Evaluation and Mapping of the Existing Situation in Selected Monuments/Spaces, PROSPELASIS project Deliverable, AUTh, Thessaloniki.

Naniopoulos, A., Giannakos, C., Xenakis, C., Papanikolaou, E., Kalliagra, S., Sakantamis, K., Kourbeti, C., Gerasimidis, S., Koufaki, I., Vavelidou, C., Pasia, A. and Karagiorgos, F. (2011a), Proposal of Functional Solutions in Final Study Level for Selected Monuments/Spaces, PROSPELASIS project Deliverable, AUTh, Thessaloniki.

Naniopoulos, A. et al. (2011b), Handbook of Basic Principles for the Realization of Accessibility Improvements in Monumental Spaces, PROSPELASIS project Deliverable, AUTh, Thessaloniki.

National Disability Authority of Ireland (NDA) (2011), Code of Practice on Accessible Heritage Sites, NDA, Dublin.

PROSPELASIS Team (2012), D7: Interventions Realized in Selected Monuments, PROSPELASIS project Deliverable, AUTh, Thessaloniki.

Royal National Institute for the Blind (RNIB) (1995), Building Sight, JMU, London.

Royal National Institute for the Blind (RNIB) (2003), The Talking Images Guide, RNIB, London.

Transport Systems Research Group of AUTh (TSRG) (2005), "Checklist for the evaluation of municipal buildings", Euvatos Polis Project Deliverable, Thessaloniki.

Tsalis, P. and Naniopoulos, A. (2008), Needs of People with Disabilities in Tourist Activities, MEDRA Project Deliverable, Toroslar.

UNESCO (1982), "Mexico City declaration on cultural policies", World Conference on Cultural Policies, Mexico City, 26 July-6 August.

UNESCO (1996), "Our Creative Diversity", report of the World Commission on Culture and Development, UNESCO, Paris.

UNESCO (2010), "The power of culture for development", No. CLT/2010/WS/14, UNESCO, Paris.

United Nations (UN) (2006), "Convention on the Rights of Persons with Disabilities", UN, New York, NY.

United Nations (UN) (2008), "International Recommendations for Tourism Statistics 2008", UN, Madrid, New York, NY.

Van der Auwera, S. and Schramme, A. (2014), "Cultural heritage policies as a tool for development: discourse or harmony?", ENCATC Journal of Cultural and Policy, Vol. 4 No. 1, pp. 4-8.

Weisen, M. (2003), "Online access to cultural and educational resources for disabled people: a European challenge", Access to Culture and Sports for People with Disabilities Conference Proceedings, Hellenic Ministry of Culture, Thessaloniki, 30 October-1 November.

\section{Further reading}

EU Commission (2014), "Mapping skills and training needs to improve accessibility in tourism services", EU Commission.

United Nations (1996), "Accessibility for the disabled”, available at: www.un.org/esa/socdev/enable/designm/ (accessed 10 October 2008).

\section{Corresponding author}

Dr Panagiotis Tsalis can be contacted at: ptsalis@civil.auth.gr

For instructions on how to order reprints of this article, please visit our website:

www.emeraldgrouppublishing.com/licensing/reprints.htm

Or contact us for further details: permissions@emeraldinsight.com 